\title{
The Robust Quay Crane Allocation for a Discrete Bulk Material Handling Port
}

\author{
Saurabh Pratap ${ }^{1}$, Manoj Kumar B, Naoufel Cheikhrouhou ${ }^{2}$, Prabal Pratap ${ }^{3}$, Manoj Kumar Tiwari ${ }^{1}$ \\ ${ }^{1}$ Department of Industrial \& Systems Engineering, Indian Institute of Technology, Kharagpur, India \\ ${ }^{2}$ Haute école de gestion de Genève, University of Applied Sciences Western Switzerland, 1227 \\ Geneva, Switzerland \\ ${ }^{3}$ Department of Electrical Engineering, National Institute of Technology, Kurukshetra, Haryana, India
}

(Email id: s.pratapiitkgp@gmail.com; manojkumrb@gmail.com; naoufel.cheikhrouhou@hesge.ch; prabalpr@gmail.com; mkt09@hotmail.com

\begin{abstract}
This study investigates the quay crane allocation problem with respect to vessel assigned to a particular discrete berth at a bulk material handling port. In the proposed model, vessels at the anchorage are berthed on a First in first out (FIFO) basis at the port, and then the quay cranes are assigned to the berth dynamically before berthing and during unloading of the vessel. To solve the model, we used the Block Based Genetic Algorithm (BBGA) and Genetic Algorithm (GA). Computational study is conducted using the real data provided by a port located on the eastern coast of India.
\end{abstract}

Keyword: Quay crane allocation; Optimization; Marine System; Genetic Algorithm

\section{INTRODUCTION}

The economic growth of a country is highly correlated with its import/export. There are three primary modes of transportation: Sea side Transport, Air side Transport, Land side Transport. Among these three modes, Sea side is the cheapest mode of transportation. Sea side transportation is further classified as sea side operation, and land side operation at the port. While addressing the key issues faced by ports, most researchers focus only on the container port terminals, and consider the berth allocation and quay crane allocation with respect to it; seldom considering the bulk material handling port. The complexity of this problem is high as assigning the quay crane is to be done before ship berths, and during the unloading of cargo. It is a dynamic assignment of quay crane allocation problem. In this paper, our main focus is to allocate the berth on the basis of a given ship schedule and allocate the quay crane to berthed ship during unloading of cargoes at the port.

The decision of berthing of ship is mainly considered by port management. Some ports follow a priority rule, and some FIFO. In this paper, we consider the berth allocation to be done on the basis of First in First out philosophy with dynamic allocation of quay crane at port. Due to the complex nature of minimization of operational time of berthed ship and unloading the cargo as early as possible, a decision support model is proposed to solve and provide the solution.

Cargo ships arrive at the anchorage and wait until the port manager calls them to berth. Port manager assigns the tug boat to guide the cargo ship from anchorage through the channel to the available berth. Only one ship can pass through the channel at a time. After berthing, ship fastening operations and quay crane allocation is done. A methodology is proposed to solve the problem of minimizing the berthed time of ship in this paper.

This research work proposes a model to achieve and optimize dynamic quay crane allocation for a cargo ship at the bulk material handling port.

\section{LITERAURE REVIEW}

Most of the researchers considered the berth allocation and quay crane allocation for the container terminal handling port. Among these two, sometimes they considered separate and sometimes they focused on the integrated model of berth and quay crane allocation model. Wang et al. [1] described a model for quay crane allocation for container terminal by considering data mining and improve the port efficiency. Gharehgozli et al. [2] proposed a model for quay crane scheduling and used the exact method to obtain the optimize result. Meisel \& Bierwirth [3] described a model based on berth allocation and quay crane allocation and minimize the handling time of vessels. Li et al. [4] proposed a model for discrete yard crane allocation for container terminal handling port and minimize the handling operations. Fu et al. [5] proposed an integrated model for quay crane 
assignment and scheduling problem. Turkogulları et al. [6] introduced an integrated model of berth allocation and time variant quay crane assignment. Liang et al. [7] proposed a model for quay crane assignment problem and determine the berthing position, time of each ship and number of quay crane assigned to each ship. The berth allocation and quay crane allocation problem [8] is prime aspect of sea side operation, where port planner allocate the quay crane on the basis of ship allocation to available berth. Bierwirth \& Meisel [9] described the berth allocation and quay crane scheduling and allocation problem for various scenario. Imai et al. [10] introduced a model for multi user container terminal address the integrate model for berth allocation and quay crane allocation simultaneously.

\section{Problem Statement}

Now, we consider a realistic scenario of port located in the eastern cost of India as shown in figure 1 (schematic view of port). In this port, there is an anchorage (where Ship S1, S2 ...S5 wait for berthing), 3 berths (Berth 1, Berth 2 and Berth 3), 5 ship quay cranes (Q) and a channel to pass one ship from anchorage to berth. The ships arrive at anchorage and on the basis of berth availability, port management allow the ship for berthing and if there is no free berth at that time, then ships (S1, S2 ..S5) wait to get berthed until next berth is available.

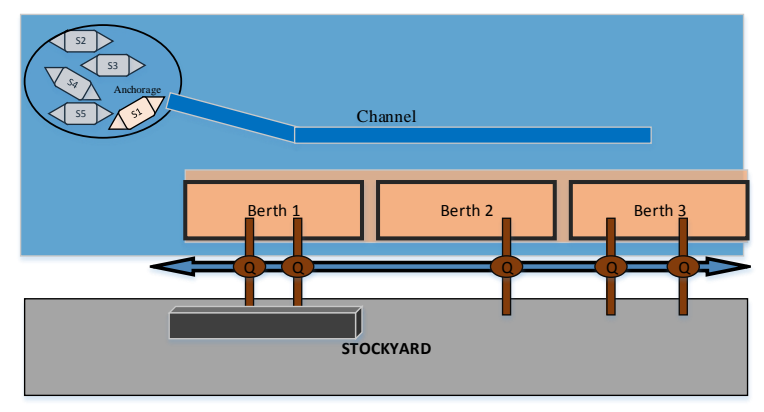

Figure 1.Schematic view of Port

In this model, we introduced a berth allocation problem, aimed at minimizing the total time the ships stay at the port. The problem is dynamic in nature, as the number of quay cranes assigned to each ship can be changed with time, to increase or decrease the unloading rate from the ship. A berth allocation is viewed as a sequential order of ships based on FIFO as the channel allows only one ship at a time. Fleet of ship is waiting on the anchorage, when berth is free, then port management allow the ship through the channel to get berthed according to first come first serve basis.
The port has a fixed number of quay cranes. The unloading rate is considered constant as all the quay cranes are assumed to have equal capacity. The model assumptions are as follows:

(1) All berths are discrete and identical with each other. Any cargo vessel can be berthed in any free berth.

(2) The rate of unloading and capacity for each quay crane is same.

(3) In a given berth, only one ship can be served at a time.

(4) The maximum number of quay cranes that can be assigned to a ship is limited. This assumption is aligned with berth length constraint.

(5) The time to move a quay crane from one berth to another is negligible.

(6) The estimated arrival time of a vessel at the anchorage and the quantity of cargo are known in advance.

\section{Notation:}

Indices

$i(=1,2, \ldots \ldots n) \epsilon$ Set of Ships $v$

$j(=1,2, \ldots . . b) \in$ Set of berths B

\section{Parameters}

$r \quad$ Rate of unloading by quay cranes

$t$ Maximum number of berths that can be assigned to each berth at a time

$a_{i} \quad$ Arrival time of Ship $i$

$c_{i} \quad$ Load Carried by Ship $i$

$f_{m i} \quad=1$ if $m^{\text {th }}$ ship berthed is the first ship after ship $i$ is unloaded

\section{Decision variables}

$\begin{array}{ll}s_{i} & \text { Berthing time of ship } i \\ d_{i} & \text { Departure time of ship } i \\ q_{m j} & \text { Number of quay cranes assigned to ship } i \\ & \text { when } m^{\text {th }} \text { ship is berthed } \\ x_{i j} & =1 \text { if ship } i \text { is berthed in berth } j\end{array}$

\section{Objective Function}

minimize

$\sum_{i=1}^{n} d_{i}-a_{i}$ 


$$
\begin{aligned}
& s_{i} \geq a_{i} \quad \forall i \in v \\
& d_{i} \geq s_{i} \quad \forall i \in v \\
& q_{m j} \leq t \quad \forall m \in v, \forall j \in B \\
& \sum_{j=1}^{b} x_{i j}=1 \quad \forall i \in v \\
& \sum_{j=1}^{b} x_{i j} \leq 1 \quad \forall j \in B \\
& \sum_{k=i+1}^{n} s_{k} x_{k j} \geq d_{i} x_{i j} \quad \forall i \in v, \forall j \in B \\
& I\left(\sum_{j=1}^{b}\left(\sum_{m=1}^{p} r q_{m j}\left(s_{m+1}-s_{m}\right)\right) \leq M\left(1-f_{p j}\right)\right. \\
& \forall i \in v, \forall j \in B, \forall p \in\{1,2 . . n\} \\
& m-p-1>M\left(1-f_{m j}\right) \\
& \forall m, p \in v, \forall j \in B \\
& p-m-1>M\left(1-f_{m j}\right) \\
& \forall m, p \in v, \forall j \in B \\
& \sum_{j=1}^{b} d_{i} x_{i j} \geq \sum_{j=1}^{b} s_{i} x_{i j}+ \\
& \sum_{j=1}^{b} \sum_{m=i}^{n}\left(s_{m+1} x_{m+1}-s_{m} x_{m}\right)\left(1-f_{m j}\right)+ \\
& \frac{c_{i}-\sum_{j=1}^{b}\left(\sum_{m=1}^{n} r q_{m j}\left(s_{m+1}-s_{m}\right)\left(\left(1-f_{m j}\right)\right)\right.}{\sum_{m=i+1}^{n} r q_{m j} f_{m j}} \\
& s_{i}, d_{i} \in R^{+}, q_{m j} \in I, x_{i j} \in\{0,1\}
\end{aligned}
$$

Equation (1) states the objective function of minimizing total time that a ship stays at the port. Equation (2) and (3) show the feasibility of berth allocation. Equation (4) puts restriction on the number of quay cranes allowed in a berth at a time. Equation (5) ensures that every ship is berthed and unloaded. Equation (6) implies a ship can be berthed in only berth. Equation (7) states the relation between the departure time of a ship and berthing time of subsequent ships in that berth. Equation (8) finds the $p$ for which there is cargo still available to be unloaded in ship $i$ where $I(x)=x$ if $x>0$ and $\mathrm{M}$ is a big number. To find the first ship after it has been completely unloaded, equation (9) and equation (10) are used to establish $m=p+1$. Equation (11) shows the relation between departure and berthing time of a ship. The first part of equation (11) is the berthing time. The second part is the time between the subsequent arrivals until the ship is still not unloaded. The third part is the time taken to unload the cargo still remaining in the ship. Equation (12) is the non-negativity and domain constraint.

\section{METHODOLOGY}

The vehicle flow scheduling and job shop scheduling on land side up to yard and manufacturing industry respectively have been studied and shown to NP hard problem[11] [12]. We use the block based genetic algorithm to obtain the quay crane allocation. Hence in the present work, we develop two heuristic methods for dynamic quay crane allocation and compare their results. First heuristic is based on Block based genetic algorithm (BBGA) and second on Genetic algorithm (GA). In this section, we present BBGA in details while discussion upon working of GA is skipped as GA is a pretty known algorithm. .

\section{Block Based Genetic Algorithm}

Block Based Genetic Algorithm (BBGA) has been used to solve the hard complex problem of job shop scheduling [12]. In this technique, we develop the block of varying size of fit chromosomes and these fit schema from the building block of chromosomes for future generations.

\section{Chromosome Representation}

Each Chromosome is divided into as many section as number of berths at the port, each section has number of strings equal to total number of free quay cranes at the port yard. The Chromosomes represents the sequence of quay crane served the vessel/ship at the berth.

\section{Creation of Block}

In this, we have to form block of highly fit chromosomes by identify the hidden pattern inside them. These hidden patterns are extracted from probability matrix of each quay crane given at the fit position of chromosomes.

\section{Block Recombination}

Once the blocks have been created, they are enrolled to generate the chromosomes for next generation. Chang et al. [12] used the recombination function to create the chromosome, similarly we use the same function.

\section{Fitness Evaluation}

In this, we have evaluated the fitness function on the basis of objective function.

\section{Selection}

We generate the new chromosome in equal number to the initial population. These Chromosome along with 
the chromosome from previous iterations and the elite set of chromosome from all previous generation give rise to $2 n+x$.

Where, $n$ is number of population.

$x$ is elite population.

\section{Termination}

The algorithm stops after a number of iterations, which was identified by number of computational experiments.

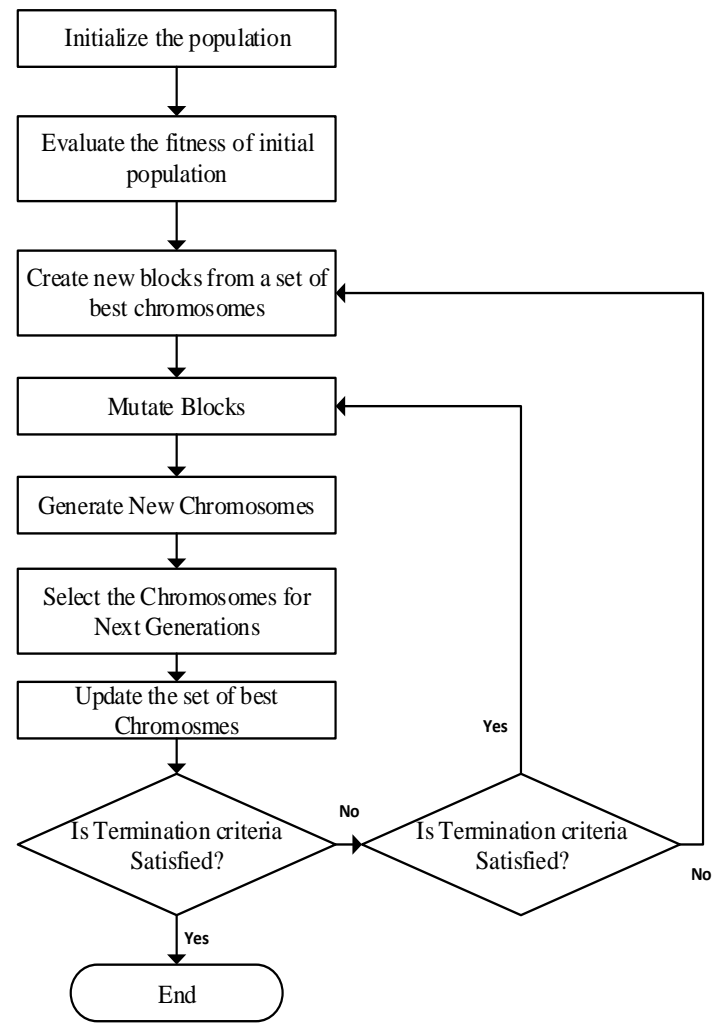

Figure 2: Flowchart of BBGA

\section{RESULTS}

The first in first out ship scheduling berth allocation is considered to solve the quay crane allocation problem. The parameters adopted are: Population Size 10, Mutation probability is equal to 0.1 and crossover probability is equal to 0.65 , Generation 100 .

In this paper, a case study of port situated at the eastern cost of India is explored. We have tested the data set of a month to obtain the near optimal result of quay crane allocation. The Figure 2 shows the objective value function using GA and BBGA.

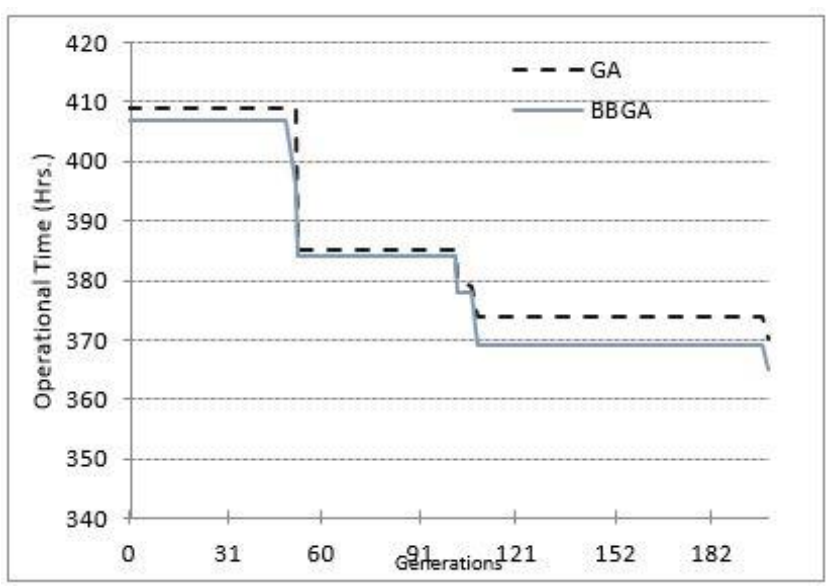

Figure 3: Objective Value function vs Generations

The computational experiments are developed on a number of problem instances as described in Table 1. The operational time of ship operations through allocating optimal quay crane allocation to the berth by GA and BBGA are as shown in Table 1 .

Table 1: Computational Experiments

\begin{tabular}{|c|c|c|c|c|}
\hline Instances & $\begin{array}{c}\text { No. of } \\
\text { berths }\end{array}$ & $\begin{array}{c}\text { No. of } \\
\text { Quay } \\
\text { Cranes }\end{array}$ & $\begin{array}{c}\text { Operating } \\
\text { Time } \\
(\mathrm{BBGA}) \\
\text { in Hrs. }\end{array}$ & $\begin{array}{c}\text { Operating } \\
\text { Time } \\
(\mathrm{GA}) \text { in } \\
\text { Hrs. }\end{array}$ \\
\hline 1 & 3 & 6 & $312(92)$ & $316(105)$ \\
\hline 2 & 3 & 5 & $260(89)$ & $265(101)$ \\
\hline 3 & 3 & 7 & $238(81)$ & $240(98)$ \\
\hline 4 & 3 & 8 & $379(96)$ & $386(103)$ \\
\hline 5 & 4 & 6 & $346(86)$ & $353(91)$ \\
\hline 6 & 4 & 8 & $289(90)$ & $300(98)$ \\
\hline 7 & 4 & 7 & $310(97)$ & $317(106)$ \\
\hline 8 & 5 & 6 & $262(88)$ & $267(92)$ \\
\hline 9 & 5 & 7 & $251(93)$ & $260(97)$ \\
\hline 10 & 5 & 8 & $246(95)$ & $251(108)$ \\
\hline
\end{tabular}

Regarding operating time, a ship schedule (FIFO) for berth allocation is considered to be evaluated using BBGA and GA. In the operating time column for BBGA and GA, the number inside the brackets shows the number of generations in which the Metaheuristics converge for the same value. It is evident from the results that BBGA gives better results than GA.

\section{CONCLUSION}

This paper capture the real life scenario of Port located at the eastern Coast of India by considering Ship 
schedule (FIFO), arrival time, and unloading rate of quay cranes.

The problem is formulated as a single objective quay crane allocation problem to minimize the operational time of ship. To solve the quay crane allocation problem, we proposed to metaheuristic method: Genetic Algorithm (GA) and Block Based Genetic Algorithm (BBGA). A comparative study is done between GA and BBGA, where it is perceived that BBGA gives better result than GA.

\section{REFERENCES}

[1] Y. Wang, Y. Huang, H. Zheng, and D. Chang, "Quay Crane Allocation of Container Terminal Based on Cluster Analysis," J. Softw., vol. 8, no. 5, pp. 1201-1208, 2013.

[2] A. H. Gharehgozli, Y. Yu, R. de Koster, and J. T. Udding, "An exact method for scheduling a yard crane," Eur. J. Oper. Res., vol. 235, no. 2, pp. 431447, Jun. 2014.

[3] F. Meisel and C. Bierwirth, "Heuristics for the integration of crane productivity in the berth allocation problem," Transp. Res. Part E Logist. Transp. Rev., vol. 45, no. 1, pp. 196-209, Jan. 2009.

[4] W. Li, Y. Wu, M. E. H. Petering, M. Goh, and R. De Souza, "Discrete time model and algorithms for container yard crane scheduling," Eur. J. Oper. Res., vol. 198, no. 1, pp. 165-172, 2009.

[5]

Y. M. Fu, A. Diabat, and I. T. Tsai, "A multi-vessel quay crane assignment and scheduling problem: Formulation and heuristic solution approach," Expert Syst. Appl., vol. 41, no. 15, pp. 6959-6965, 2014.

[6] Y. B. Türkoğulları, Z. C. Taşkın, N. Aras, and İ. K. Altınel, "Optimal berth allocation and timeinvariant quay crane assignment in container terminals," Eur. J. Oper. Res., vol. 235, pp. 88-101, Oct. 2014.

[7] C. Liang, Y. Huang, and Y. Yang, "A quay crane dynamic scheduling problem by hybrid evolutionary algorithm for berth allocation planning," Comput. Ind. Eng., vol. 56, no. 3, pp. 1021-1028, Apr. 2009.

[8] Z. a. Hu, "A quay crane assignment approach for berth allocation problem in container terminal," in 3rd International Symposium on Intelligent Information Technology and Security Informatics, IITSI 2010, 2010, pp. 17-21.
[9] C. Bierwirth and F. Meisel, "A survey of berth allocation and quay crane scheduling problems in container terminals," Eur. J. Oper. Res., vol. 202, no. 3, pp. 615-627, 2010.

[10] A. Imai, H. C. Chen, E. Nishimura, and S. Papadimitriou, "The simultaneous berth and quay crane allocation problem," Transp. Res. Part E Logist. Transp. Rev., vol. 44, pp. 900-920, 2008.

[11] E. K. Bish, T. Leong, C. Li, J. W. C. Ng, and D. Simchi- Levi, "Analysis of a new vehicle scheduling and location problem," Nav. Res. Logist., vol. 48, no. 5, pp. 363-385, 2001.

[12] P.-C. Chang, M.-H. Chen, M. K. Tiwari, and A. S. Iquebal, "A block-based evolutionary algorithm for flow-shop scheduling problem," Appl. Soft Comput., vol. 13, no. 12, pp. 4536-4547, 2013. 